Original research article

\title{
Pharmacological stroke prevention in the elderly with atrial fibrillation in Poland - Results of PolSenior study
}

\author{
Beata Łabuz-Roszak ${ }^{a, *}$, Michał Skrzypek ${ }^{b}$, \\ Agnieszka Machowska-Majchrzak ${ }^{c}$, Małgorzata Mossakowska ${ }^{d}$, \\ Jerzy Chudek ${ }^{e}$, Andrzej Więcek ${ }^{f}$, Krystyna Pierzchała ${ }^{c}$, \\ Beata Łącka-Gaździk ${ }^{g}$, Tomasz Grodzicki ${ }^{h}$ \\ a Department of Basic Medical Sciences, Faculty of Public Health, Medical University of Silesia, Katowice, Poland \\ ${ }^{\mathrm{b}}$ Department of Biostatistics, Faculty of Public Health, Medical University of Silesia, Katowice, Poland \\ ${ }^{\mathrm{c}}$ Department of Neurology, Medical Faculty in Zabrze, Medical University of Silesia, Katowice, Poland \\ ${ }^{\mathrm{d}}$ International Institute of Molecular and Cell Biology, Warsaw, Poland \\ ${ }^{\text {e }}$ Department of Pathophysiology, Medical Faculty in Katowice, Medical University of Silesia, Katowice, Poland \\ ${ }^{\mathrm{f}}$ Department of Nephrology, Transplantation and Internal Medicine, Medical Faculty in Katowice, Medical University \\ of Silesia, Katowice, Poland \\ ${ }^{\mathrm{g}}$ Department of Nephrology, Diabetology and Internal Diseases, Medical University of Silesia, Katowice, Poland \\ ${ }^{\mathrm{h}}$ Department of Internal Diseases and Gerontology, Jagiellonian University Collegium Medicum, Krakow, Poland
}

\section{A R T I C L E I N F O}

Article history:

Received 11 April 2017

Accepted 4 July 2017

Available online 11 July 2017

\section{Keywords:}

Atrial fibrillation

Elderly

Direct oral anticoagulant drugs

Oral antiplatelet drugs

Acetylsalicylic acid

\begin{abstract}
A B S T R A C T
Introduction: Atrial fibrillation (AF) is the most frequent clinically significant arrhythmia, especially common in the elderly. As it is known, AF is associated with increased risk of stroke. Little is known about pharmacological cardiovascular prevention in the elderly with AF in Poland.

Objectives: The purpose of the study was to evaluate the frequency of pharmacological stroke prevention among the elderly with AF in Poland and its association with clinical characteristics and concomitant cardiovascular risk factors.

Patients and methods: The analysis included elderly ( $\geq 65$ years) participants of the PolSenior study performed in years 2008-2012.

Results: The study group consisted of 4979 people (mean age: $79.3 \pm 8.7$ years). Among them, there were 875 patients (18.7\%) with documented history of AF. Pharmacological prevention with the use of vitamin K antagonists (VKA) was applied by 117 (13.4\%) of the elderly with AF, including 15 (1.7\%) on dual therapy. Additionally, 386 (45.3\%) subjects with AF were using oral antiplatelet therapy (OAPs), mostly aspirin. Acenocoumarol was much more often used than warfarin. New oral anticoagulant drugs (NOACs) were not used at all. Only personal income was associated with the use of VKA. No significant correlation was found for the age, sex, place of residence and level of education.
\end{abstract}

\footnotetext{
* Corresponding author at: Department of Basic Medical Sciences, Faculty of Public Health, Medical University of Silesia, Piekarska 18, 41902 Bytom, Poland. Tel.: +48 605097110.

E-mail address: broszak@sum.edu.pl (B. Łabuz-Roszak). http://dx.doi.org/10.1016/j.pjnns.2017.07.005 0028-3843/@ 2017 Published by Elsevier Sp. z o.o. on behalf of Polish Neurological Society.
} 
Conclusions: The study was unique to determine the frequency of pharmacological stroke prevention among elderly people with AF in Poland. It occurred that oral anticoagulant drugs were applied too rarely in this group of patients. Educational programs should be developed among general practitioners concerning current recommendations for patients with AF.

(C) 2017 Published by Elsevier Sp. z o.o. on behalf of Polish Neurological Society.

1.

\section{Introduction}

Atrial fibrillation (AF) is the most common clinically significant arrhythmia and one of the most important cardiovascular risk factors, especially in the elderly [1]. According to the latest studies the prevalence of AF in the general population of most European countries is about 2\% [2-4] and - as it was shown in some meta-analyses - it doubled in the last decade [5]. The prevalence of AF increases with aging. In subjects younger than 49 years it is present in $0.12-0.16 \%$, in those aged $60-70$ years - in 3.7-4.2\%, and in people aged 80 or older in 10-17\% [58]. As it was described in our previous paper, AF was present in almost $20 \%$ of Polish people aged 65 years or older [9].

As it is well known, AF is associated with increased risk of stroke $[5,10,11]$. It is estimated that $A F$ is responsible for about $20 \%$ of strokes (so called cardiogenic strokes) [12]. According to the latest guidelines [13-16] in all subjects with $\mathrm{AF}$ oral anticoagulant drugs should be considered using $\mathrm{CHA}_{2} \mathrm{DS}_{2} \mathrm{VASc}$ or - or less recommended - $\mathrm{CHADS}_{2}$ score [17].

Little is known about pharmacological cardiovascular prevention in the elderly with atrial fibrillation in Poland. Therefore, the purpose of the study was to evaluate the frequency of use of cardiovascular pharmacological preventive therapy among the elderly with $\mathrm{AF}$ in Poland and its association with clinical characteristics and concomitant cardiovascular risk factors.

\section{Patients and methods}

The study was based on the data collected during the implementation of a multicenter, publicly funded research project commissioned by the Polish Ministry of Science and Higher Education called "Medical, psychological, sociological and economic aspects of aging of people in Poland (PolSenior)" (PBZ-MEiN-9/2/2006). A detailed description of the project has been previously published [9]. The project was carried out from October 2008 to April 2012. It was approved by the Bioethics Commission.

The study group included respondents from the PolSenior project aged 65 years and older with documented history of atrial fibrillation (AF).

The following data from the general PolSenior database were used and analyzed: age, sex, place of residence (rural or urban), level of education, personal income, a history of other cardiovascular risk factors, BMI. The frequency of use of drugs was based on the data collected in the medical part of the questionnaire.

Statistical data analysis was performed using SAS version 9.2 (SAS Institute Inc., Gary, NC). The level of statistical significance was $P<0.05$. The following tests were used: the chi-square test, Fischer's exact test, the Shapiro-Wilk test, the Student's t-test, the Wilcoxon rank sum test, and a model of logistic regression. The $\mathrm{CHADS}_{2}$ score was calculated according to the general rules [17].

\section{Results}

The PolSenior study group consisted of 4979 people (mean age: $79.4 \pm 8.7$ years). Among them, there were 875 patients $(18.7 \%)$ with documented history of AF.

There were 455 women (52.0\%) and 420 men (48.0\%). The mean age of the examined subjects was $78.7 \pm 8.0$ years, similar for women and men $(78.3 \pm 8.0$ vs. $79.1 \pm 8.0$ years, respectively, $P=0.12$ ).

Among all the examined subjects with AF, 498 subjects (56.9\%) used at least one drug in pharmacological prevention of thromboembolic complications of AF. In turn, OAPs were regularly used by 396 subjects (45.3\%), whereas vitamin $\mathrm{K}$ antagonists (VKAs) by 117 subjects (13.4\%). One OAP was used by $362 \mathrm{AF}$ subjects (41.4\%), two different OAPs by 34 (3.9\%). On the other hand, one VKA was used by 109 (12.5\%) and two VKAs by 8 subjects (0.9\%). Additionally, 15 persons (1.7\%) simultaneously used OAP and VCA (Table 1). New oral anticoagulants (NOACs) were not used at all.

The $\mathrm{CHADS}_{2}$ score was calculated in 679 people (lack of full required subset of data in 196 cases). Treatment with OAPs or VKAs according to the $\mathrm{CHADS}_{2}$ score is presented in Table 2.

The percentage of women using OAPs and/or VKAs $(57.9 \%$; $n=243$ ) was similar as the corresponding percentage of men ( $n=255 ; 56.0 \% ; P=0.59$ ).

Also the mean age $(78.7 \pm 7.7$ years) of respondents taking VKAs and/or OAPs was similar to the mean age $(78.8 \pm 8.5$ years) of those with AF not treated with these drugs $(P=0.89)$.

Table 1 - Frequency of use OAPs and VKAs in the study group ( $\mathbf{N}=\mathbf{8 7 5})$.

\begin{tabular}{|c|c|c|}
\hline & $\begin{array}{l}\text { International } \\
\text { drug name }\end{array}$ & $\begin{array}{c}\text { Number of } \\
\text { respondents } \\
\text { using the drug } \\
n(\%)\end{array}$ \\
\hline \multirow[t]{3}{*}{ OAPs $(n=396)$} & Acetylsalicylic acid & 387 (44.2\%) \\
\hline & Clopidogrel & $22(2.5 \%)$ \\
\hline & Ticlopidine & $21(2.4 \%)$ \\
\hline \multirow[t]{2}{*}{ VKAs $(n=117)$} & Acenocoumarol & $112(12.8)$ \\
\hline & Warfarin & $13(1.5 \%)$ \\
\hline
\end{tabular}


Table 2 - Management of AF in people with calculated CHADS $_{2}$ score $(n=679)$.

\begin{tabular}{lccc} 
Drugs & \multicolumn{3}{c}{$\mathrm{CHADS}_{2}$} \\
\cline { 2 - 4 } & 0 points & 1 point & $\geq 2$ points \\
& $\mathrm{N}=33$ & $\mathrm{~N}=138$ & $\mathrm{~N}=508$ \\
\hline OAPs & $7(21.2 \%)$ & $47(34.1 \%)$ & $254(50 \%)$ \\
VKAs & - & $14(10.1 \%)$ & $76(15 \%)$ \\
\hline \multicolumn{2}{l}{ OAPs - oral antiplatelet drugs, VKAs - vitamin K antagonists. } \\
\hline
\end{tabular}

Most of examined subjects lived in cities $(66.4 \% ; n=580)$. No difference was found between urban $(n=327 ; 56.4 \%)$ and rural areas residents $(n=170 ; 57.8 \%)(P=0.68)$ concerning pharmacological prevention of stroke in AF. Also no significant differences were observed between different regions of Poland (data not shown).

No correlation was found between the frequency of use of OAPs and/or VKAs in subjects with $\mathrm{AF}$ and the level of education (Table 3).

Personal income had a significant effect on the frequency of use of VKAs $(P<0.01)$, but not OAPs (Table 3$)$. Only $10.8 \%$ of participants with the lowest personal income (less than 1000 Polish zloty per month) used VKAs in comparison with $25.9 \%$ of those with the highest income (2001 and more Polish zloty per month) (Table 4).

The frequency of other cardiovascular risk factors in the study group is presented in Table 5 . The association between the use of OAPs and/or VKAs in AF subjects and the presence or the absence of other cardiovascular risk factors is presented in Table 6.

The logistic regression analysis was made to find which other risk factor was mostly associated with preventive therapy. Among all of the cardiovascular risk factors,
Table 5 - Frequency of other cardiovascular risk factors in PolSenior study participants with atrial fibrillation

( $\mathbf{N}=\mathbf{8 7 5}$ ).

\begin{tabular}{lcc} 
Risk factor & $n(\%)$ & ND $(n)$ \\
\hline Previous stroke & $105(12.6 \%)$ & 4 \\
Pharmacologically treated hypertension & $718(82.1 \%)$ & - \\
Previus myocardial infarct & $197(23.5 \%)$ & 35 \\
Coronary heart disease & $293(35.1 \%)$ & 41 \\
$\quad$ (without myocardial infarct) & $265(31.8 \%)$ & 41 \\
Congestive heart failure & $203(23.3 \%)$ & 5 \\
Pharmacologically treated diabetes mellitus & $308(35.2 \%)$ & - \\
Pharmacologically treated dyslipidemia & $59(6.8 \%)$ & 2 \\
Current smoker & $627(76.7 \%)$ & 57 \\
Overweight/obesity (BMI $\left.\geq 25 \mathrm{~kg} / \mathrm{m}^{2}\right)$ & \\
\hline BMI - body mass index, ND - not documented. & \\
\hline
\end{tabular}

hypertension and dyslipidemia were mostly associated with OAP treatment, and previous stroke was associated with VCA treatment (Table 7).

\section{Discussion}

According to the ESC guidelines 2016 oral anticoagulation therapy to prevent thromboembolism is recommended for all male AF patients with score 2 or more in $\mathrm{CHA}_{2} \mathrm{DS}_{2}$-VASc (female with score 3 or more) and should be considered in male AF patients with score 1 (female with score 2). Antiplatelet monotherapy is not recommended for stroke prevention in $\mathrm{AF}$ patients, regardless of stroke risk $[16,17]$.

All of the examined in these study patients with AF had at least one additional risk factor - age $\geq 65$ years (estimated $\mathrm{CHA}_{2} \mathrm{DS}_{2}$-VASc was $\geq 1$ ) so in all male patients and most of female patients oral anticoagulants should be considered. As

Table 3 - Pharmacological cardiovascular prevention and education ( $n=843$, ND in 32 examined subjects).

\begin{tabular}{|c|c|c|c|c|}
\hline Level of education & $n$ & $\begin{array}{c}\text { OAP and/or VCA } \\
n(\%)\end{array}$ & $\begin{array}{l}\text { OAP } \\
n(\%)\end{array}$ & $\begin{array}{l}\text { VCA } \\
n(\%)\end{array}$ \\
\hline Incomplete elementary & 89 & $54(60.7 \%)$ & $42(47.2 \%)$ & $12(13.5 \%)$ \\
\hline Complete elementary & 374 & $213(57.0 \%)$ & $180(48.1 \%)$ & $38(10.2 \%)$ \\
\hline Professional & 112 & $62(55.4 \%)$ & $48(42.9 \%)$ & $16(14.3 \%)$ \\
\hline High school & 194 & $106(54.6 \%)$ & 75 (38.7\%) & $34(17.5 \%)$ \\
\hline University & 74 & $46(62.2 \%)$ & 36 (48.7\%) & $15(20.3 \%)$ \\
\hline$P$ & & 0.76 & 0.25 & 0.06 \\
\hline
\end{tabular}

Table 4 - Association between personal income and OAPs and VKAs usage ( $n=717$, ND in 158).

\begin{tabular}{|c|c|c|c|c|}
\hline Personal income zloty/mouth & $n$ & $\begin{array}{c}\text { OAP and/or VKA } \\
n(\%)\end{array}$ & $\begin{array}{l}\text { OAP } \\
n(\%)\end{array}$ & $\begin{array}{l}\text { VKA } \\
n(\%)\end{array}$ \\
\hline Less than 1000 & 277 & $156(56.3 \%)$ & $129(46.6 \%)$ & 30 (10.8\%) \\
\hline $1001-1500$ & 245 & 137 (55.9\%) & 101 (41.2\%) & 40 (16.3\%) \\
\hline 1501-2000 & 114 & $66(57.9 \%)$ & $56(49.1 \%)$ & $12(10.5 \%)$ \\
\hline 2001 and more & 81 & 56 (69.1\%) & 40 (49.4\%) & $21(25.9 \%)$ \\
\hline$P$ & & 0.18 & 0.39 & $<0.01$ \\
\hline
\end{tabular}


Table 6 - Frequency of use of OAP and/or VKA in association with presence ( + ) or absence ( - ) of cardiovascular risk factors. Data presented as $n(\%)$.

\begin{tabular}{|c|c|c|c|c|}
\hline Risk factor & & $\begin{array}{c}\text { OAP and/or VKA } \\
n(\%)\end{array}$ & $\begin{array}{l}\text { OAP } \\
n(\%)\end{array}$ & $\begin{array}{l}\text { VKA } \\
n(\%)\end{array}$ \\
\hline \multirow[t]{3}{*}{ Previous stroke } & $(+)$ & 73 (69.5\%) & 53 (50.5\%) & 21 (20.0\%) \\
\hline & $(-)$ & $423(55.2 \%)$ & $341(44.5 \%)$ & $96(12.5 \%)$ \\
\hline & $P$ & $<0.01$ & 0.25 & 0.04 \\
\hline \multirow[t]{3}{*}{ Pharmacologically treated hypertension } & $(+)$ & $451(62.8 \%)$ & $354(49.3 \%)$ & $112(15.6 \%)$ \\
\hline & $(-)$ & 47 (29.9\%) & 42 (26.8\%) & $5(3.2 \%)$ \\
\hline & $P$ & $<0.01$ & $<0.01$ & $<0.01$ \\
\hline \multirow[t]{3}{*}{ Previous myocardial infarct } & $(+)$ & $127(64.5 \%)$ & 110 (55.8\%) & 26 (13.2\%) \\
\hline & $(-)$ & $351(54.6 \%)$ & $273(42.5 \%)$ & $83(12.9 \%)$ \\
\hline & $P$ & 0.01 & $<0.01$ & 0.92 \\
\hline \multirow[t]{3}{*}{ Coronary heart disease (without myocardial infarct) } & $(+)$ & $196(66.9 \%)$ & $159(54.3 \%)$ & $48(16.4 \%)$ \\
\hline & $(-)$ & $276(51.0 \%)$ & $221(40.9 \%)$ & $58(10.7 \%)$ \\
\hline & $P$ & $<0.01$ & $<0.01$ & 0.02 \\
\hline \multirow[t]{3}{*}{ Congestive heart failure } & $(+)$ & $176(66.4 \%)$ & $131(49.4 \%)$ & $51(19.3 \%)$ \\
\hline & $(-)$ & $296(52.0 \%)$ & $248(43.6 \%)$ & $56(9.8 \%)$ \\
\hline & $P$ & $<0.01$ & 0.11 & $<0.01$ \\
\hline \multirow[t]{3}{*}{ Pharmacologically treated diabetes mellitus } & $(+)$ & $118(58.1 \%)$ & $94(46.3 \%)$ & $24(11.8 \%)$ \\
\hline & $(-)$ & $380(57.0 \%)$ & $302(45.3 \%)$ & $93(13.9 \%)$ \\
\hline & $P$ & 0.77 & 0.80 & 0.44 \\
\hline \multirow[t]{3}{*}{ Pharmacologically treated dyslipidemia } & $(+)$ & $237(77.0 \%)$ & $186(60.4 \%)$ & $63(20.5 \%)$ \\
\hline & $(-)$ & $261(46.0 \%)$ & $210(37.0 \%)$ & $54(9.5 \%)$ \\
\hline & $P$ & $<0.01$ & $<0.01$ & 0.01 \\
\hline \multirow[t]{3}{*}{ Current smoker } & $(+)$ & $35(59.3 \%)$ & $29(49.2 \%)$ & $6(10.2 \%)$ \\
\hline & $(-)$ & $462(56.8 \%)$ & $367(45.1 \%)$ & $110(13.5 \%)$ \\
\hline & $P$ & 0.70 & 0.54 & 0.47 \\
\hline \multirow[t]{3}{*}{ Overweight/obesity (BMI $\geq 25 \mathrm{~kg} / \mathrm{m}^{2}$ ) } & $(+)$ & $369(58.9 \%)$ & $280(44.7 \%)$ & $102(16.3 \%)$ \\
\hline & $(-)$ & $106(55.5 \%)$ & $94(49.2 \%)$ & $14(7.3 \%)$ \\
\hline & $P$ & 0.41 & 0.27 & $<0.01$ \\
\hline \multirow[t]{3}{*}{ Sex } & $\mathrm{F}$ & $255(56.0 \%)$ & $209(45.9 \%)$ & $50(11.0 \%)$ \\
\hline & M & $243(57.9 \%)$ & $187(44.5 \%)$ & $67(16.0 \%)$ \\
\hline & $P$ & 0.59 & 0.68 & 0.03 \\
\hline
\end{tabular}

BMI - body mass index, VKA - vitamin K antagonists, F - female, M - male, OAP - oral antiplatelet drugs, (+) - risk factor present, (-) - risk factor not present.

Table 7 - Association of cardiovascular risk factors with OAP and/or VKA treatment. Data are presented as OR (95\%CI) and Pvalue.

\begin{tabular}{|c|c|c|c|c|c|c|}
\hline \multirow[t]{2}{*}{ Risk factor } & \multicolumn{2}{|c|}{ OAP and/or VKA } & \multicolumn{2}{|l|}{ OAP } & \multicolumn{2}{|l|}{ VKA } \\
\hline & OR $(95 \% \mathrm{CI})$ & $P$ & OR $(95 \% \mathrm{CI})$ & $P$ & OR $(95 \% \mathrm{CI})$ & $P$ \\
\hline Previous stroke & $2.44(1.36-4.37)$ & $<0.01$ & $1.18(0.72-1.95)$ & 0.51 & $2.34(1.28-4.28)$ & 0.01 \\
\hline Pharmacologically treated hypertension & $3.64(2.33-5.69)$ & $<0.01$ & $2.65(1.68-4.18)$ & $<0.01$ & $3.60(1.4-9.28)$ & 0.01 \\
\hline Previous myocardial infarct & $1.07(0.71-1.60)$ & 0.75 & $1.45(1.00-2.10)$ & 0.05 & $0.77(0.45-1.31)$ & 0.33 \\
\hline Coronary heart disease (without myocardial infarct) & $1.37(0.96-1.94)$ & 0.08 & $1.39(1.00-1.93)$ & 0.05 & $1.17(0.73-1.85)$ & 0.52 \\
\hline Congestive heart failure & $1.63(1.14-2.35)$ & 0.01 & $1.06(0.76-1.49)$ & 0.73 & $1.89(1.20-3.00)$ & 0.01 \\
\hline Pharmacologically treated diabetes mellitus & $0.91(0.62-1.33)$ & 0.61 & $1.00(0.69-1.43)$ & 0.98 & $0.66(0.38-1.15)$ & 0.14 \\
\hline Pharmacologically treated dyslipidemia & $2.88(2.02-4.11)$ & $<0.01$ & $2.04(1.47-2.81)$ & $<0.01$ & $1.82(1.16-2.85)$ & 0.01 \\
\hline Current smoker & $1.18(0.63-2.21)$ & 0.62 & $1.14(0.63-2.07)$ & 0.66 & $0.83(0.33-2.10)$ & 0.69 \\
\hline Overweight/obesity (BMI $\geq 25 \mathrm{~kg} / \mathrm{m}^{2}$ ) & $0.83(0.57-1.23)$ & 0.35 & $0.61(0.42-0.88)$ & 0.01 & $2.75(1.37-5.54)$ & $<0.01$ \\
\hline $\operatorname{Sex}(M / F)$ & $1.14(0.83-1.58)$ & 0.42 & $0.90(0.66-1.23)$ & 0.52 & $1.77(1.13-2.78)$ & 0.01 \\
\hline
\end{tabular}

follows from our analysis, only about $13 \%$ of the examined elderly with AF had used oral anticoagulants, slightly over $45 \%$ - OAPs. The most popular drug used by our respondents was ASA (44.2\%). Currently, ASA is not recommended any more.
Acenocoumarol was much more popular than warfarin - it was used by $12.8 \%$ of elderly in comparison to $1.5 \%$ of warfarin users. Such situation was probably associated with low availability and higher price of warfarin in the period when 
the study was conducted. NOAC were not used by the elderly examined in PolSenior study because they were not available in the period when the research was done (in Europe dabigatran and rivaroxaban were registered in 2011, and apixaban - in 2012).

It seemed that oral anticoagulants were applied too rarely among older people with AF in Poland, both as primary or secondary pharmacological preventive therapy - only slightly more than $20 \%$ of elderly after stroke used VKAs. It is comparable to the data presented by some other Polish authors for that period; Bednarski at al. found that oral anticoagulants were prescribed in only $39 \%$ of people with AF at discharge from the hospital (despite high stroke risk calculated by $\mathrm{CHA}_{2} \mathrm{DS}_{2} \mathrm{VASc}$ or $\mathrm{CHADS}_{2}$ scale) [18].

In the PREFER in AF registry (Prevention of thromboembolic events - European Registry in Atrial Fibrillation) the authors collected data from patients in seven European countries (Austria, France, Germany, Italy, Spain, Switzerland, and the UK) [19]. In this study 7245 patients were enrolled, in the mean age of $71.5+11$ years. It was conducted from January 2012 to January 2013, so only slightly later than the PolSenior study. But the results are completely different. Among all the PREFER in AF subjects, $94.2 \%$ had at least 1 point in $\mathrm{CHA}_{2} \mathrm{DS}_{2}$ VASc score (in PolSenior study $100 \%$ - because of age). But in this European study oral anticoagulants were used by $82.3 \%$ of all examined people with AF and by $84 \%$ of subjects with at least 1 point in $\mathrm{CHA}_{2} \mathrm{DS}_{2}$ VASc (VCAs - 78\%; NOACs - 6.1\%). OAPs as monotherapy were only used by $11.3 \%$ of people. The most rarely oral anticoagulants were used in Italy $(71 . \%)$, the most often in France (90\%).

Also other registries from period 2005-2008 in Europe revealed that usage of oral anticoagulants in AF was much higher in other European countries (about 70\%) than in Poland $[20,21]$.

Recent studies showed similar trends [22,23]. Stepinska et al. described the baseline data from the GARFIELD-AF registry (an ongoing prospective, multicenter, international registry of patients newly diagnosed with AF) in Europe. The use of VKAs was generally higher in other European countries $(41.9-55.5 \%)$ than in Poland (36.9-41.7\%). The patients in this study were younger (median age 67).

The only factor associated with the frequency of use of oral anticoagulants in subjects with AF in this study was personal income, similarly to our previous paper, concerning general usage of oral pharmacological stroke prevention in the whole PolSenior population [9]. No significant correlation was found for the age, sex, place of residence and level of education.

Summarizing, oral anticoagulants for stroke prevention among elderly patients were used too infrequently and aspirin was overused in Poland in 2008-2012. It is necessary to carry out the current research in similar population of older AF patients.

\section{Limitation of the study}

Atrial fibrillation, coronary heart disease and congestive heart failure were recognized only when they were documented. Because lack of all data to calculate $\mathrm{CHA}_{2} \mathrm{DS}_{2} \mathrm{VASc}$, less recommended $\mathrm{CHADS}_{2}$ was used. HAS-BLED scale could not be also calculated because of the lack of required data. It is an analysis of data from a remote period 2008-2012.

\section{Conflict of interest}

None declared.

\section{Acknowledgement and financial support}

Implemented under publicly-funded project No. PBZ-MEIN-9/ 2/2006, Ministry of Science and Higher Education.

\section{R E F E R E N C E S}

[1] Sienkiewicz-Jarosz H, Głuszkiewicz M, Pniewski J, Niewada M, Członkowska A, Wolfe C, et al. Incidence and case fatality rates of first-ever stroke - comparison of data from two prospective population-based studies conducted in Warsaw. Neurol Neurochir Pol 2011;45:207-12.

[2] Murphy NF, Simpson CR, Jhund PS, Stewart S, Kirkpatrick M, Chalmers J, et al. A national survey of the prevalence, incidence, primary care burden and treatment of atrial fibrillation in Scotland. Heart 2007;93:606-12.

[3] Ruskin JN, Singh JP. Atrial fibrillation endpoints: hospitalizations. Heart Rhythm 2004;1:B31-5.

[4] Santini M, De Ferrari GM, Pandozi C, Pittrow D, Willow SD, Kirchoff D, et al. Atrial fibrillation requiring urgent medical care. Approach and outcome in the various departments of admission. Data from the Atrial Fibrillation/Flutter Italian Registry (FIRE). Ital Heart J 2004;5:205-13.

[5] Zoni-Berisso M, Lercari F, Carazza T, Domenicucci S. Epidemiology of atrial fibrilation: European perspective. Clin Epidemiol 2014;6:213-20.

[6] Friberg L, Bergfeldt L. Atrial fibrillation prevalence revisited. J Intern Med 2013;274:461-8.

[7] Zoni-Berisso M, Filippi A, Landolina M, Brignoli O, D'Ambrosio G, Maglia G, et al. Frequency, patient characteristics, treatment strategies, and resource usage of atrial fibrillation [From the Italian Survey of Atrial Fibrillation Management (ISAF) Study]. Am J Cardiol 2013;111:705-11.

[8] Cowan C, Healicon R, Robson I, Long WR, Barrett J, Fay M, et al. The use of anticoagulants in the management of atrial fibrillation among general practices in England. Heart 2013;99:1166-72.

[9] Łabuz-Roszak B, Pierzchała K, Skrzypek M, Swiech M, Machowska-Majchrzak A. Oral anticoagulant and antiplatelet drugs used in prevention of cardiovascular events in elderly people in Poland. BMC Cardiovasc Disord 2012;12:98.

[10] Friberg L, Hammar N, Rosenqvist M. Stroke in paroxysmal atrial fibrillation: report from the Stockolm Cohort of Atrial Fibrillation. Eur Heart J 2010;31:967-72.

[11] Shroff GR, Solid CA, Herzog CA. Temporal trends in ischemic stroke and anticoagulation therapy among Medicare patients with atrial fibrillation: a 15-year perspective (1992-2007). JAMA Intern Med 2013;173:159-60.

[12] Pierzchała K, Łabuz-Roszak B, Gajewska A, Nowiński M, Zając M. Analiza czynników ryzyka chorób naczyniowych mózgu u chorych leczonych w pododdziale udarowym. Wiad Lek 2006;59:44-7.

[13] January CT, Wann LS, Alpert JS, Calkins H, Cigarroa JE, Cleveland Jr JC, et al. 2014 AHA/ACC/HRS guideline for the management of patients with atrial fibrillation: executive 
summary: a report of the American College of Cardiology/ American Heart Association Task Force on Practice Guidelines and the Heart Rhythm Society. J Am Coll Cardiol 2014;64:2246-80.

[14] Camm AJ, Lip GYJ, Caterina R, Savelieva I, Atar D, Hohnloser SH, et al. 2012 focused update of the ESC Guidelines for the management of atrial fibrillation. Eur Heart J 2012;33: 2719-47.

[15] Camm AJ, Kirchhof P, Lip GY, Schotten U, Savalieva I, Ernst $\mathrm{S}$, et al. Guidelines for the management of atrial fibrillation: the task force for the management of atrial fibrillation of the European Society of Cardiology (ESC). Eur Heart J 2010;31:2369-429.

[16] Kirchhof P, Benussi S, Kotecha D, Ahlsson A, Atar D, Casadei B, et al. 2016 ESC Guidelines for the management of atrial fibrillation developed in collaboration with EACTS. The Task Force for the management of atrial fibrillation of the European Society of Cardiology (ESC) developed with the special contribution of the European Heart Rhythm Association (EHRA) of the ESC endorsed by the European Stroke Organisation (ESO). Eur Heart J 2016;50: e1-88.

[17] Patel AA, Nelson WW, Schein J. Impact of $\mathrm{CHA}_{2} \mathrm{DS}_{2}$ VASc score on candidacy for anticoagulation in patients with atrial fibrillation: a multipayer analysis. Clin Ther 2016;38. 2196-203.e5.

[18] Bednarski J, Cieszewska E, Strzelecki A, Filipiak KJ. Anticoagulant and antiplatelet therapy for stroke prevention in atrial fibrillation patients in the clinical practice of a single district hospital in Poland. Kardiol Pol 2013;71:1260-5.

[19] Kirchhof P, Ammentorp B, Darius D, Caterina RD, LeHeuzey JY, Schilling RJ, et al. Management of atrial fibrillation in seven European countries after the publication of the 2010 ESC Guidelines on atrial fibrillation: primary results of the PREvention of thromboembolic events - European Registry in Atrial Fibrillation (PREFER in AF). Europace 2014;16:6-14.

[20] Nieuwlaat R, Olsson SB, Lip GY, Camm AJ, Breithardt G, Capucci A, et al. Guideline-adherent antithrombotic treatment is associated with improved outcomes compared with undertreatment in high-risk patients with atrial fibrillation. The Euro Heart Survey on Atrial Fibrillation. Am Heart J 2007;153:1006-12.

[21] Nabauer M, Gerth A, Limbourg T, Schneider S, Oeff M, Kirchhof P, et al. The Registry of the German Competence NETwork on Atrial Fibrillation: patient characteristics and initial management. Europace 2009;11:423-34.

[22] Stępińska J, Kremis E, Konopka A, Wożakowska-Kapłon B, Ruszkowski P, Kukla P, et al. Stroke prevention in atrial fibrillation patients in Poland and other European countries: insights from the GARFIELD-AF registry. Kardiol Pol 2016;74(4):362-71.

[23] Lenarczyk R, Mitręga K, Mazurek M, Janion M, Opolski G, Drożdż J, et al. Polish and European management strategies in patients with atrial fibrillation. Data from the EURObservational Research Programme-Atrial Fibrillation General Registry Pilot Phase (EORP-AF Pilot). Pol Arch Med Wewn 2016;126(3):138-48. 